\title{
Uso da geração fotovoltaica para viabilização de projetos de Mecanismo de
}

\section{Desenvolvimento Limpo}

\author{
Use of photovoltaic generation for feasibility of Clean Development Mechanism projects \\ Uso de generación fotovoltaica para viabilizar proyectos del Mecanismo de Desarrollo Limpio
}

Recebido: 17/09/2021 | Revisado: 25/09/2021 | Aceito: 29/09/2021 | Publicado: 02/10/2021

\author{
Evellyn Aryadne Costa França \\ ORCID: https://orcid.org/0000-0002-6241-3746 \\ Universidade da Amazônia, Brasil \\ E-mail: evellynaryadne@homail.com \\ Marco Valério de Albuquerque Vinagre \\ ORCID: https://orcid.org/0000-0002-7650-9204 \\ Universidade da Amazônia, Brasil \\ E-mail: valeriovinagre@gmail.com \\ Natália Daniele de Lima Vinagre Fonseca \\ ORCID: https://orcid.org/0000-0002-9535-6012 \\ Faculdade de Arquitetura da Universidade de Lisboa, Portugal \\ E-mail: nataliafonseca@ campus.ul.pt \\ Maria do Socorro Bezerra Lopes \\ ORCID: https://orcid.org/0000-0003-1650-4724 \\ Universidade da Amazônia, Brasil \\ E-mail: soclopes@gmail.com \\ Marcio José Moutinho da Ponte \\ ORCID: https://orcid.org/0000-0002-0724-3721 \\ Universidade Federal do Oeste do Pará, Brasil \\ E-mail: marcio.ponte@ufopa.edu.br \\ Alberto Carlos de Melo Lima \\ ORCID: https://orcid.org/0000-0002-8752-7432 \\ Universidade do Estado do Pará, Brasil \\ E-mail: acmlima@gmail.com
}

\begin{abstract}
Resumo
O Mecanismo de Desenvolvimento Limpo (MDL) é um instrumento de flexibilização apresentado no Protocolo de Quioto para projetos de redução de emissão de Gases do Efeito Estufa. Este artigo tem por objetivo estudar o uso e a viabilidade de projetos MDL em sistemas fotovoltaicos. Utilizou-se a metodologia do MDL adequada para geração de energia renovável conectada à rede, calculou-se as reduções de emissões de $\mathrm{CO} 2$ e as Reduções Certificadas de Emissões (RCEs) a fim de determinar a geração fotovoltaica necessária para obter projetos de MDL viáveis. A aplicação do projeto de MDL apresenta viabilidade econômica ao projeto de geração fotovoltaica mesmo não apresentando uma diferença significativa em termos econômicos considerado os indicadores econômicos calculados sem o MDL. A menor Rentabilidade obtida sem e com a aplicação do MDL foi, respectivamente, $243 \%$ e $102 \%$, considerando o período total de vida útil do projeto fotovoltaico de 25 anos. Pode-se considerar que esses resultados apresentariam uma diferença mais significativa em gerações superiores ao apresentado neste estudo.
\end{abstract}

Palavras-chave: Energia renovável; Redução de emissões de carbono; Geração de energia conectada à rede; Projeto de pequena escala; Indicadores econômicos.

\begin{abstract}
The Clean Development Mechanism (CDM) is a flexible instrument presented in the Kyoto Protocol for projects to reduce the emission of Greenhouse Gases. This article aims to study the use and feasibility of CDM projects in photovoltaic systems. The CDM methodology required for grid-connected renewable energy generation was used, calculated as $\mathrm{CO} 2$ emission reductions and as Certified Emission Reductions (CERs) to determine the photovoltaic generation needed to obtain viable CDM projects. An application of the CDM project presents economic feasibility to the photovoltaic generation project even though it does not change a difference in economic terms considering the economic indicators calculated without the CDM. The lowest profitability obtained without and with the application of the CDM was, respectively, $243 \%$ and $102 \%$, considering the total useful life of the photovoltaic project of 25 years. It can be considered that these results would present a more important difference in generations superior to the present study.
\end{abstract}

Keywords: Renewable energy; Carbon emission reduction; Grid power generation; Small scale project; Economic indicators. 


\section{Resumen}

El Mecanismo de Desarrollo Limpio (MDL) es un instrumento flexible presentado en el Protocolo de Kioto para proyectos de reducción de emisiones de Gases de Efecto Invernadero. Este artículo tiene como objetivo estudiar el uso y la viabilidad de proyectos MDL en sistemas fotovoltaicos. Se utilizó la metodología MDL requerida para la generación de energía renovable conectada a la red, calculada como reducciones de emisiones de CO2 y como Reducciones Certificadas de Emisiones (RCEs) para determinar la generación fotovoltaica necesaria para obtener proyectos MDL viables. Una aplicación del proyecto MDL presenta factibilidad económica al proyecto de generación fotovoltaica, aunque no cambia una diferencia en términos económicos considerando los indicadores económicos calculados sin el MDL. La menor rentabilidad obtenida sin y con la aplicación del MDL fue, respectivamente, $243 \%$ y $102 \%$, considerando la vida útil total del proyecto fotovoltaico de 25 años. Se puede considerar que estos resultados presentarían una diferencia más importante en generaciones superiores al presente estudio.

Palabras clave: Energías renovables; Reducción de emisiones de carbono; Generación de energía conectada a la red; Proyecto de pequeña escala; Indicadores económicos.

\section{Introdução}

A partir das décadas de 60 e 70, as questões ambientais passaram a ser mais discutidas por parte da comunidade científica, principalmente devido ao aumento da degradação ambiental e ao uso intensivo de combustíveis fósseis. Diante disso, a Organização das Nações Unidas (ONU) passou a promover debates mundiais a respeito das questões ambientais. Em 1992, na Conferência das Nações Unidas sobre Meio Ambiente e Desenvolvimento no Rio de Janeiro foi adotada a Convenção Quadro das Nações Unidas sobre Mudanças do Clima, do inglês United Nations Framework Convention on Climate Change (UNFCCC), com o principal objetivo de estabilizar as concentrações de Gases de Efeito Estufa (GEE) na atmosfera causadas pelas interferências antrópicas (Padilha, 2009; Lopes, 2013).

Em 1997 em Quioto, Japão, foi realizada a $3^{\mathbf{a}}$ edição da Conferência das Nações Unidas sobre o Meio Ambiente e Desenvolvimento, com a representação de mais de 160 países. Nessa conferência foram estabelecidas metas e prazos para redução ou limitação das emissões de GEE, presentes no Protocolo de Quioto. Para ajudar os países presentes no Protocolo de Quioto a cumprirem suas metas, ajudar o setor privado e os países em desenvolvimento, as reduções de emissões assumiram valores econômicos por estabelecimento de instrumentos de flexibilização estabelecidos no Protocolo, dentre eles o Mecanismo de Desenvolvimento Limpo (MDL) (Lopes, 2013).

O MDL permite que países desenvolvidos financiem projetos com redução de emissões de GEE em países em desenvolvimento a fim de cumprirem suas metas estabelecidas no Protocolo de Quioto. Dentre os projetos que podem ser executados no Mecanismo de Desenvolvimento Limpo, tem-se os voltados ao setor energético que utilizam fontes renováveis de energia favorecendo a redução das emissões de Gases de Efeito Estufa (Lopes, 2013).

O aproveitamento da energia gerada pelo sol é uma das alternativas energéticas mais promissoras para promover a energia necessária para o desenvolvimento humano (Pinho \& Galdino, 2014). Este estudo utiliza da energia solar fotovoltaica que é aquela obtida através da conversão direta da luz solar em corrente elétrica, utilizando células fotovoltaicas, para avaliar a viabilidades dessa geração de energia nos Projetos de MDL.

O Brasil apresenta média de irradiação dentro da faixa de $3,5 \mathrm{kWh} / \mathrm{m}^{2}$.dia a $6,25 \mathrm{kWh} / \mathrm{m}^{2}$.dia, apresentando seguintes médias em cada uma das cinco regiões do país: $5,49 \mathrm{kWh} / \mathrm{m}^{2}$.dia na região nordeste; $5,07 \mathrm{kWh} / \mathrm{m}^{2}$.dia na região centro-oeste; 5,06 na região sudeste; $4,64 \mathrm{kWh} / \mathrm{m}^{2}$.dia na região norte; e 4,53 kWh/m².dia na região sul. Além disso, o país apresenta alto nível e baixa variabilidade de irradiação em comparação com os valores dos países da União Europeia, onde a utilização de projetos com aproveitamento de recursos solares é amplamente disseminada. A Alemanha e França, por exemplo, apresentam média de irradiação de aproximadamente $3,0 \mathrm{kWh} / \mathrm{m}^{2}$.dia e $3,5 \mathrm{kWh} / \mathrm{m}^{2}$.dia, respectivamente (Pereira, Martins, Abreu \& Ruther, 2006; Pereira et al., 2017).

Em termos de capacidade instalada de geração fotovoltaica o Brasil ainda está em expansão. Um dos principais empecilhos para o crescimento da utilização dos sistemas fotovoltaicos é o seu custo. No entanto essa tecnologia tem ganhado 
destaque inclusive por razões antes não tão discutidas, como a questão dos impactos ambientais (Pinho \& Galdino, 2014). A utilização de sistemas fotovoltaicos tem apresentado crescimento exponencial, principalmente após a Resolução Normativa nº482 da Agência Nacional de Energia Elétrica (ANEEL) em 2012, permitindo que ocorra a troca de energia com a rede elétrica. Essa resolução favoreceu a utilização dos sistemas fotovoltaicos em residências.

Diante desse contexto, viu-se a possibilidade de avaliar a geração econômica com os benefícios ambientais gerados pela redução das emissões de GEEs com a utilização de uma fonte de geração de energia que está em expansão no país aplicada a projetos de Mecanismo de Desenvolvimento Limpo desenvolvidos em edificações residenciais e comerciais. A investigação pretende quantificar os custos do desenvolvimento e aplicação de projetos de Mecanismo de Desenvolvimento Limpo e observar se apresentam maior viabilidade econômica quando aplicado em sistemas de geração de energia fotovoltaica conectada à rede caracterizado em projeto de pequena escala quando comparado aos sistemas de geração que não estão aplicados ao projeto MDL. Parte-se da hipótese que a comercialização das reduções de emissões de GEEs obtidas com a aplicação do projeto do MDL irá apresentar maior rentabilidade econômica aos sistemas de geração de energia fotovoltaica.

Neste artigo, apresenta-se a metodologia de projetos de MDL que pode ser aplicada na geração fotovoltaica conectada à rede de energia elétrica, com o objetivo de investigar o uso de projetos de MDL em sistemas fotovoltaicos e a viabilidade da aplicação desses projetos, por meio da análise da viabilidade econômica do uso de energia solar fotovoltaica em unidades consumidoras de diferentes classes tarifárias, além de quantificar a relação de investimentos realizados na implantação do projeto MDL, calculando o retorno financeiro dos projetos. O trabalho é composto por embasamento teórico e estudos da geração solar fotovoltaica integrada à rede.

Esta pesquisa foi dividida em seis tópicos. O primeiro é a introdução. O segundo trata sobre o Protocolo de Quioto, o desenvolvimento de projetos de Mecanismo de Desenvolvimento Limpo e como é feita a comercialização das reduções de emissões. O terceiro tópico discorre a respeito da geração da energia fotovoltaica. O quarto tópico aborda a metodologia adotada na pesquisa, indicando a metodologia de MDL adotada, como foram quantificadas as reduções de emissões de Gases de Efeito Estufa, o sistema de geração fotovoltaico utilizado, bem como os indicadores econômicos selecionados, a elaboração de cenários e os custos envolvidos no projeto MDL. O quinto tópico apresenta os resultados e discussão obtidos por meio dos cálculos e da análise da viabilidade econômica do projeto. Por fim, no sexto tópico apresentam-se as considerações finais.

\section{O Protocolo de Quioto e o Mecanismo de Desenvolvimento Limpo - MDL}

O Protocolo de Quioto estabeleceu reduções dos níveis de emissões dos Gases de Efeito Estufa, sendo eles: dióxido de carbono $\left(\mathrm{CO}_{2}\right)$, metano $\left(\mathrm{CH}_{4}\right)$, óxido nitroso $\left(\mathrm{N}_{2} \mathrm{O}\right)$, hexafluoreto de enxofre $\left(\mathrm{SF}_{6}\right)$, e famílias de hidrofluorocarbonos $(\mathrm{HFCs})$ e perfluorocarbonos (PFCs) (Padilha, 2009; Lopes, 2013).

O Protocolo apresenta entre seus pontos básicos (Ribeiro, 2005):

a) Os mecanismos para remoção ou redução dos GEEs;

b) Estabelecimento de limites de emissões de GEEs para cada parte envolvida;

c) Determinação de quotas de redução de GEEs para os países signatários, do Anexo I do Protocolo de Quioto, tendo como base os volumes de emissões no ano de 1990;

d) Conciliação entre interesses e necessidades dos países mais ricos e aqueles desprovidos de recursos para reduzir as emissões de GEEs, bem como removê-los.

Apresenta possibilidades para os países desenvolvidos cumprir os seus compromissos em relação a redução e limitação da emissão de GEE por meio de mecanismos de Mercado. O Comércio de Emissões/Instrumento de Flexibilização pode ser por (United Nations Framework Convention on Climate Change [UNFCCC], 1998): Implementação Conjunta - IC (em inglês, Join Implementation), Comércio de Emissões - CE (em inglês, Emissions Trading) e Mecanismo de 
Desenvolvimento Limpo - MDL (em inglês: Clean Development Mechanism - CDM), sendo esse último o instrumento de flexibilização utilizado nesse estudo.

O Mecanismo de Desenvolvimento Limpo é o único instrumento de flexibilização que pode ser realizado por meio da participação voluntária de países em desenvolvimento (United Nations Framework Convention on Climate Change [UNFCCC], 2016).

Os projetos de MDL visam o desenvolvimento sustentável e a diminuição de Gases de Efeito Estufa, sendo representados pelo dióxido de carbono equivalente $\left(\mathrm{CO}_{2} \mathrm{e}\right)$. Os projetos são baseados em uma Linha de Base, que é a representação, das emissões antropogênicas de GEE por fontes de emissão que ocorreriam se não houvesse o projeto de redução de emissões, e as toneladas evitadas de $\mathrm{CO}_{2}$ com o projeto poderão ser negociadas através da venda das Reduções Certificadas de Emissões - RCEs no mercado mundial (Padilha, 2009). Para a execução de projetos o MDL é requerido a aplicação de uma metodologia básica para monitoramento da quantidade de Reduções Certificadas de Emissões - RCEs (UNFCCC, 2016).

De acordo com a UNFCCC, até o ano de 2016, existiam 7.690 projetos de MDL no mundo, no qual a China ocupava o primeiro lugar contendo 3.764 projetos, a Índia em segundo abrangendo 1.598 e o Brasil em terceiro comportando 339 projetos registrados (Ministério da Ciência, Tecnologia e Inovações [MCTI], 2017).

O mesmo relatório de 2016 apresenta os tipos de atividades de projeto no MDL executados no Brasil, são elas: hidrelétrica, biogás, usina eólica, gás de aterro, biomassa energética, substituição de combustível fóssil, metano evitado, decomposição de $\mathrm{N}_{2} \mathrm{O}$, utilização e recuperação de calor, reflorestamento e florestamento, uso de materiais, eficiência energética, substituição de $\mathrm{SF}_{6}$, redução e substituição de $\mathrm{PFC}$ e energia solar fotovoltaica; este último apresentando apenas um único projeto registrado no MDL (MCTI, 2017).

Para que um projeto obtenha as Reduções Certificadas de Emissões, as atividades do projeto do MDL devem necessariamente passar pelas sete etapas do ciclo do projeto, conforme demostrado na Figura 1.

Figura 1. Ciclo de desenvolvimento de um Projeto MDL e responsáveis por cada etapa.

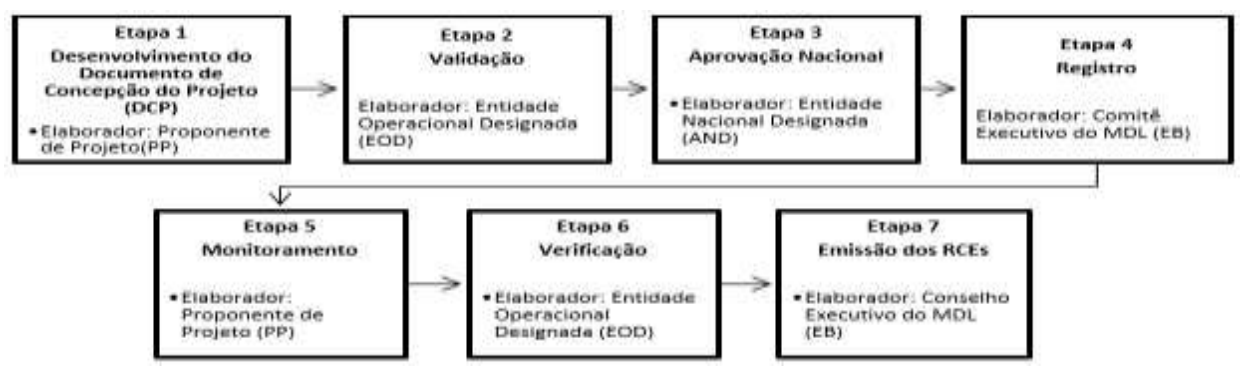

Fonte: Adaptado de "Status dos Projetos do Mecanismo de Desenvolvimento Limpo (MDL) no Brasil: Última compilação do site da UNFCCC e da CIMGC: 31 de janeiro de 2016" de MCTI, 2017.

Os projetos de MDL podem ser de modalidade de Grande ou Pequena escala. Os procedimentos para o desenvolvimento do MDL originalmente foram desenvolvidos para projetos de grande porte, entretanto esses procedimentos dizem respeito à regra mais geral e são aplicáveis a todos os tipos de projetos que cumprem os critérios das atividades elegíveis no âmbito do MDL (Frondizi, 2009). Buscando simplificar o ciclo de projeto e tornar mais ágil os procedimentos, além de diminuir os custos das etapas e de implantação foram criados os projetos denominados de Pequena Escala (Padilha, 2009). Estes devem se enquadrar em um dos três tipos a seguir (UNFCCC, 2016):

a) Atividades de projeto de energia renovável com capacidade máxima de produção equivalente até $15 \mathrm{MW}$; 
b) Atividades de projetos de melhoria da eficiência energética, que reduzam o consumo de energia tanto da oferta, como da demanda, em até $60 \mathrm{GWh} / \mathrm{ano}$ (ou equivalente apropriado);

c) Outras atividades de projetos que resultem em redução de emissões antropogênicas iguais ou inferiores a 60.000 $\mathrm{tCO}_{2} \mathrm{e} / \mathrm{ano}$.

O Mercado Brasileiro de Redução de Emissões foi criado no Brasil pelo Ministério do Desenvolvimento, Indústria e Comércio Exterior (MDIC), em parceria com a Bolsa de Mercadorias e Futuros (BM\&F) e auxiliados pela Fundação Getúlio Vargas (FGV) (Padilha, 2009).

O desenvolvimento do projeto MDL e a comercialização das RCEs envolvem alguns ricos que no Guia Latinoamericano do MDL (Asociación Española de la Industria Eléctrica [UNESA], 2005) são apresenta em três grupos, sendo eles: os riscos inerentes ao Protocolo de Quioto e ao MDL, os riscos relacionados ao nível das reduções de emissões no tempo planejado e os riscos relacionados ao preço futuro no mercado das RCEs.

No estudo desenvolvido por Padilha (2009), foram apresentados os valores da venda das RCEs pelos mercados que comercializam os créditos de carbono evidenciando a instabilidade dos valores que são comercializados as RCEs, O maior valor apresentado por Padilha (2009) estava em US $\$ 36,00 / \mathrm{tCO}_{2} \mathrm{e}$ no início de 2006 sofrendo uma queda para US $\$ 11,00 / \mathrm{tCO}_{2} \mathrm{e}$ em maio do mesmo ano. O menor valor apontado foi no início de 2009, apresentando um valor médio de US\$9,00/tCO 2 .

A Comissão Econômica para a América Latina e Caribe (CEPAL), indica que é possível trabalhar com a faixa de US\$ $10,00 / \mathrm{tCO}_{2}$ a US\$ 60,00/tCO $\mathrm{tC}_{2}$ para a remuneração dos RCEs em projetos de MDL na região. Entre US\$ $10,00 / \mathrm{tCO}_{2}$ e US\$ $20,00 / \mathrm{tCO}_{2}$ para projetos associados a sumidouros e resgate de carbono em atividades do setor florestal, e entre US\$ 40,00/tCO 2 e US $\$ 60,00 / \mathrm{tCO}_{2}$ para projetos na área de energia (CEBDS, 2001 apud Padilha, 2009).

Como observado por Padilha (2009), no estudo de Vieira, Barros e Toscano (2019, pp. 38-40), também é analisado como as negociações de compra e venda das RCEs estão relacionadas com o tipo de mercado, os tipos de créditos e a forma de comercialização. Além disso, os preços alteram conforme a lei de oferta e demanda. Segundo os dados de seu estudo, Vieira, Barros e Toscano (2019, p. 40), apresenta que os preços médios estabelecidos no mercado voluntário de crédito de carbono nos anos de 2009, 2010, 2011, 2012 e 2013 eram, respectivamente, US\$6,5/tCO $2 \mathrm{e}$, US $\$ 6,0 / \mathrm{tCO}_{2} \mathrm{e}$, US $\$ 6,2 / \mathrm{tCO}_{2} \mathrm{e}, \mathrm{US} \$ 5,9 / \mathrm{tCO}_{2} \mathrm{e}$ e $\mathrm{US} \$ 4,8 / \mathrm{tCO}_{2} \mathrm{e}$.

Atualmente, na Plataforma de Compensação de Carbono das Nações Unidas ${ }^{1}$ possuem projetos que os valores dos créditos de carbono variam de US $\$ 1,75 / \mathrm{tCO}_{2} \mathrm{e}$ a US $\$ 40,00 / \mathrm{tCO}_{2} \mathrm{e}$. No que se refere os projetos de energia solar, os valores dos créditos de carbono disponíveis variam de US\$2,75/tCO $\mathrm{CO}_{2} \mathrm{e} \mathrm{US} \$ 12,75 / \mathrm{t} \mathrm{CO}_{2} \mathrm{e}$.

\section{Energia Fotovoltaica}

A energia elétrica gerada pela conversão direta da luz solar ainda é pouco utilizada tendo em vista ser essa uma forma de energia presente de maneira abundante na Terra. Países como a Alemanha, Austrália, Estados Unidos e Inglaterra fazem uso dessa geração de energia por materiais fotovoltaica que integram a fachada ou cobertura de edificações a mais tempo e em alguns países desenvolvidos é realizada a concessão de incentivos para a instalação de sistemas fotovoltaicos (Pinho \& Galdino, 2014; Pereira et al., 2017). No Brasil, segundo dados da Associação Brasileira de Energia Solar Fotovoltaica (ABSOLAR) (2021), a capacidade de geração solar instalada ultrapassou os 10 gigawatts (GW) em sistemas de pequeno e médio instalados em telhados, fachadas e terrenos incluindo, além de usinas de grande porte. Com essa geração o Brasil passa a integrar a lista dos 15 países com maior capacidade de geração solar instalada.

\footnotetext{
1 A Plataforma online das Nações Unidas para o cancelamento voluntário de Reduções Certificadas de Emissões (RCEs) realiza a comercialização de crédito de carbono. Disponível em: <https://offset.climateneutralnow.org/> Acesso em: 27 set. 2021.
} 
A implantação de Sistemas Fotovoltaico no Brasil está crescendo e a cada vez a população local e os empreendedores entendem a relevância que a utilização de fontes renováveis, como a fotovoltaica, tem para a matriz elétrica nacional, principalmente nas instalações integradas para edifícios em áreas urbanas desenvolvidas (Vinagre et al., 2016).

A crescente adoção dessa geração no território brasileiro, principalmente na adoção da geração nas coberturas residenciais, se torna mais viável ou mais cara conforme a tarifa de eletricidade convencional da distribuidora local dependendo também do índice de radiação da região (Pereira et al., 2017).

A Resolução Normativa n $n^{\circ}$ 482/2012 da Agência Nacional de Energia Elétrica (ANEEL) (Agência Nacional de Energia Elétrica [ANEEL], 2012) estabelece normas e sistema de compensação para o consumidor pela energia elétrica injetada na rede. Em novembro de 2015 a Resolução Normativa $n^{\circ} 482$ foi atualizada com a publicação da Resolução Normativa $n^{\circ}$ 687/2015 (Agência Nacional de Energia Elétrica [ANEEL], 2015) com alterações a respeito da mini e da microgeração, assim como a produção de energia solar, criando novas possibilidades de negócio.

Os sistemas Fotovoltaicos são classificados como: sistemas isolados ou off grid e sistemas conectados à rede ou on grid, conforme caracterizados a seguir.

Os sistemas isolados ou off grid, são aqueles que não estão conectados à rede de distribuição de energia elétrica pública e necessitam de armazenadores para a energia gerada ser utilizada quando não há radiação solar, em geral, é utilizado banco de baterias para o armazenamento. Diante disso, esse sistema é composto pelos painéis solares fotovoltaicos que realizam a captação dos raios solares e os transformam em energia elétrica de corrente contínua (CC) que é convertida pelo inversor para corrente alternada (CA), compatível com a rede utilizada na edificação, a CA passa pelo quadro de distribuição de corrente alternada (QDCA) e alimenta os aparelhos elétricos e eletrônicos com características adequadas. O sistema também conta com um controlador de cargas para controlar o processo de carga e descarga do banco de baterias, e o conjunto/banco de baterias para armazenar a energia excedente gerada (Lamberts, Ghisi, Pereira \& Batista, 2010; Pinho \& Galdino, 2014), conforme demostra a Figura 2.

Figura 2. Componentes básicos de um sistema fotovoltaico isolado (off grid).

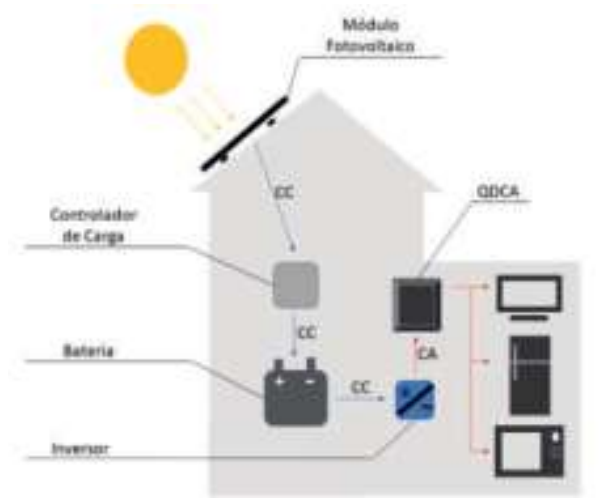

Fonte: De "Energia Solar Fotovoltaica no Brasil: Conceitos, Aplicações e Estudo de Caso" de Ayrão, 2018. Rio de Janeiro: International Copper Association Brazil.

Os sistemas conectados à rede ou on grid, dependem da rede de distribuição de energia elétrica pública sendo a energia gerada no sistema injetada diretamente à rede sem utilizar armazenadores. Nesse tipo de sistema os painéis solares fotovoltaicos captam os raios de sol e os transformam em energia elétrica de corrente contínua (CC) que é convertido pelo inversor em corrente alternada (CA) compatível com a rede elétrica local, possui um medidor bidirecional que mede a energia injetada na rede elétrica pela residência. Além de apresentar os componentes de comando e proteção, como chaves, fusíveis, 
disjuntores e quadro de distribuição de corrente alternada (QDCA) (Lamberts et al., 2010; Pinho \& Galdino, 2014), conforme demostra a Figura 3. Para este estudo serão utilizados sistemas de geração fotovoltaica conectados à rede.

Figura 3. Componentes básicos de um sistema fotovoltaico conectado à rede (on grid).

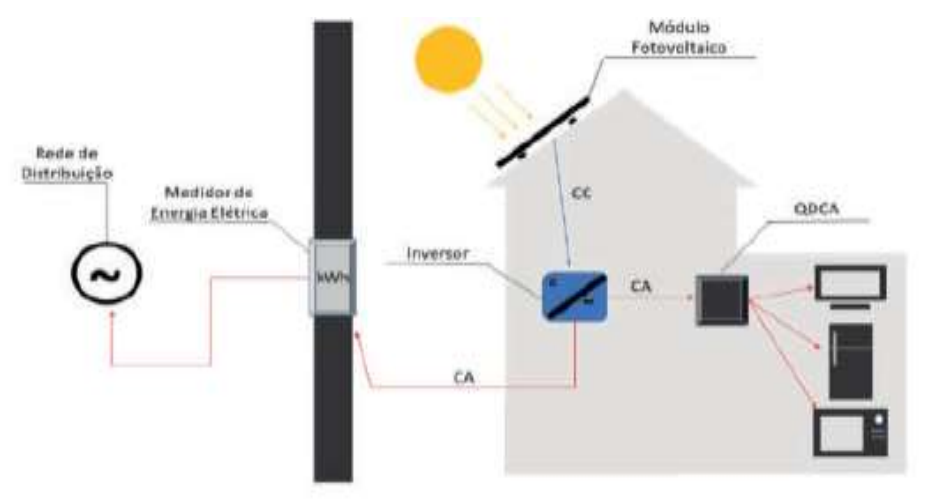

Fonte: De "Energia Solar Fotovoltaica no Brasil: Conceitos, Aplicações e Estudo de Caso" de Ayrão, 2018. Rio de Janeiro: International Copper Association Brazil.

No que se refere a eficiência energética desses sistemas, os Sistemas Fotovoltaicos Distribuídos Conectados à Rede Elétrica são considerados ideais, devido a minimização das perdas na transmissão e distribuição. Outro ponto refere-se ao fato da possibilidade de serem integrados à edificação e não necessitarem de área extra para sua instalação (Ruther, 2004).

\section{Metodologia}

Para o desenvolvimento desta investigação foi utilizado método de pesquisa aplicada, dividida em quatro etapas: 1) levantamento bibliográfico; 2) escolha da metodologia de projeto de MDL; 3) coleta de dados; 4) tratamento e análise dos dados. Estas foram desenvolvidas no decorrer de 15 meses (agosto/2018 a novembro/2019).

A primeira etapa mencionada foi desenvolvida por meio de consultas de materiais especializados, tais como, livros, artigos publicados e periódicos que abordam a temática do estudo, relatórios e informações da Convenção Quadro das Nações Unidas sobre a Mudança do Clima (UNFCCC) e resoluções normativas. Os dados obtidos nessa etapa foram apresentados nos tópicos anteriores do estado da arte sobre Protocolo de Quioto e o Mecanismo de Desenvolvimento Limpo - MDL e Energia Fotovoltaica, os mesmos serviram de base para o desenvolvimento da elaboração dos cenários das vendas das RCEs, dos custos que envolvem um projeto MDL e das etapas subsequentes, que consistem na recolha, tratamento e análise dos dados.

$\mathrm{Na}$ segunda etapa foi avaliada as metodologias do MDL aprovadas para projetos de pequena escala que estão disponíveis no site da UNFCCC ${ }^{2}$ e escolhida a metodologia que se aplica ao sistema de geração de energia fotovoltaica conectada à rede, apresentada a seguir no tópico Quantificação das Emissões.

A terceira etapa consistiu na recolha de dados sobre sistemas de geração de energia fotovoltaica. Os sistemas selecionados foram elaborados por Valente (2019) em 11 unidades consumidoras de diferentes classes tarifárias, apresentando a viabilidade econômica da utilização da geração fotovoltaica em cada unidade, porém, Valente (2019) não apresenta no estudo a quantificação e a viabilização da aplicação a Projeto de Mecanismo de Desenvolvimento Limpo. No tópico Sistema de Geração Fotovoltaica apresenta-se os indicadores econômicos utilizados no estudo de Valente (2019) que também foram avaliados nesse estudo.

\footnotetext{
${ }^{2} \mathrm{O}$ site da UNFCCC para o Mecanismo de Desenvolvimento Limpo apresenta todas as metodologias para projetos de grande e pequena escala que foram aprovadas e estão em validade (https://cdm.unfccc.int/).
} 
A última etapa corresponde ao tratamento dos dados obtidos nas etapas 1 e 3 , considerando a metodologia do Mecanismo de Desenvolvimento Limpo que se adequa ao caso da geração de energia fotovoltaica obtida na etapa 2. Por fim, foi realizada a análise dos dados para verificar a viabilidade do projeto de MDL aplicado a sistemas fotovoltaicos.

\subsection{Quantificação das Emissões}

Nessa etapa será utilizada metodologia de cálculo elaborada/aprovada pelo Comitê Executivo do MDL onde o objetivo é estimar quantitativamente as emissões evitadas de Gases de Efeito Estufa - GEE de um projeto e MDL em relação as fontes de emissões, as chamadas emissões de linha de base, e as fugas, que são as emissões do projeto. Para tal, considerouse a seguinte metodologia de MDL: AMS-I.D - "Geração de energia renovável conectada à rede".

A metodologia AMS-I.D é utilizada para projetos de geração de energia renovável, como, fotovoltaica, hidrelétrica, de maré/ondas, eólicas, geotérmicas e de biomassa renovável, com fornecimento de eletricidade a uma rede nacional ou regional ou para fornecimento de eletricidade a uma instalação de consumo identificada por meio de rede nacional/regional (United Nations Framework Convention on Climate Change [UNFCCC], 2014a). Essa metodologia também foi utilizada por Lopes (2013) para estimar a redução de emissões de GEEs em sistemas fotovoltaicos conectados à rede com geração dentro do limite máximo classificado na metodologia de 15MW.

De acordo com a metodologia adotada, na construção de novos projetos ocorre, em alguns casos, emissão de carbono, que são chamadas emissões de projeto, porém, por se tratar de energia solar fotovoltaica considera que não há emissões de projeto. Outra consideração que deve ser feita é em relação as emissões de fuga, que são aquelas decorrentes da atividade do projeto, que geralmente estão ligadas a projetos de grande escala. Os projetos de pequena escala de energia solar fotovoltaica possuem emissões de fuga nula (Lopes, 2013).

Diante disso, as reduções de emissões de $\mathrm{CO}_{2} \mathrm{e}$ de cada projeto fotovoltaico é calculada pela Equação 1, sendo (UNFCCC, 2014a):

$$
E R_{y}=B E_{y}-P E_{y}-L E_{y}(1)
$$

Onde:

$E R_{y}$ : Reduções das emissões no ano $y\left(\mathrm{tCO}_{2} \mathrm{e} / \mathrm{ano}\right)$;

$B E_{y}$ : Emissões da linha de base no ano $y$ ( $\left.\mathrm{tCO}_{2} \mathrm{e} / \mathrm{ano}\right)$;

$P E_{y}$ : Emissões do projeto no ano $y$ ( $\left.\mathrm{tCO}_{2} \mathrm{e} / \mathrm{ano}\right)$, no caso em questão é zero;

$L E_{y}$ : Emissões decorrentes das fugas no ano $y$ ( $\left.\mathrm{tCO}_{2} \mathrm{e} / \mathrm{ano}\right)$, no caso em questão é zero.

Considerando que as emissões de projeto e as emissões das fugas são nulas, as reduções de emissões será igual às emissões de linha de base e para o cálculo de emissões de linha de base $\left(B E_{y}\right)$, utiliza-se a Equação 2 (UNFCCC, 2014a):

$$
B E_{y}=E G_{P J, y} \times E F_{\text {grid, },}
$$

Onde:

$B E_{y}$ : Emissões da linha de base no ano $y\left(\mathrm{tCO}_{2} \mathrm{e} / \mathrm{ano}\right) ;$

$E G_{P J, y}$ : Quantidade líquida de eletricidade fornecida à rede elétrica como resultado da atividade de projeto de MDL no ano $y(\mathrm{MWh})$;

$E F_{\text {grid,y }}$ : Fator de emissão de $\mathrm{CO}_{2}$ de rede elétrica no ano $y\left(\mathrm{tCO}_{2} \mathrm{e} / \mathrm{MWh}\right)$.

Os componentes da Equação 2 são obtidos com a Equações 3 e Equação 4 apresentadas a seguir. A Equação 3 representa o cálculo da quantidade líquida de eletricidade fornecida à rede elétrica $\left(E G_{P J, y}\right)$ para projetos de energia solar (UNFCCC, 2014a):

$$
E G_{P J, y}=E G_{P J \_A d d, y}
$$

Onde: 
$E G_{P J \_A d d, y}$ : Quantidade de geração líquida de eletricidade fornecida à rede no ano $y$ pela planta/unidade do projeto que foi adicionada ao projeto atividade (MWh).

O cálculo do fator de emissão de $\mathrm{CO}_{2}$ da rede elétrica no ano y $\left(E F_{\text {grid,y }}\right)$ é feito considerando uma margem combinada (CM), que consiste na combinação dos fatores da margem de operação (OM) e da margem de construção (BM), conforme apresentado na Equação 4 (UNFCCC, 2014a):

$$
E F_{\text {grid, } C M, y}=E F_{\text {grid, } O M, y} \times w_{O M}+E F_{\text {grid, } B M, y} \times w_{B M}(4
$$

Onde:

$E F_{\text {grid,BM,y }}$ :Fator de emissão de $\mathrm{CO}_{2}$ da margem de construção no ano $y$ ( $\left.\mathrm{tCO}_{2} \mathrm{e} / \mathrm{MWh}\right)$;

$E F_{\text {grid,OM,y }}$ :Fator de emissão de $\mathrm{CO}_{2}$ da margem de operação no ano $y\left(\mathrm{tCO}_{2} \mathrm{e} / \mathrm{MWh}\right)$;

$w_{O M}$ : Ponderação do fator de emissão da margem de operação (\%);

$w_{B M}$ : Ponderação do fator de emissão da margem de construção (\%);

Os valores de peso da ponderação dos respectivos fatores de emissão apresentados na Equação 4 são determinados como sendo $w_{O M}=0,75$ e $w_{B M}=0,25$ para projetos de energia solar pela "Ferramenta para calcular o fator de emissão de um sistema elétrico" - Versão 07.0 (United Nations Framework Convention on Climate Change [UNFCCC], 2014b).

Os valores de Fator de emissão de $\mathrm{CO}_{2}$ tanto da margem de construção $\left(E F_{\text {grid,BM,y }}\right)$ como da margem de operação $\left(E F_{\text {grid,OM,y }}\right)$ necessários para o cálculo da Equação 4 foram obtidos no site do Ministério da Ciência, Tecnologia, Inovações e Comunicações (MCTIC) nos dados sobre Fatores de Emissão de $\mathrm{CO}_{2}$ pela geração de energia elétrica no Sistema Interligado Nacional do Brasil com ano base de $2018^{3}$. Os valores para os fatores de emissão de $\mathrm{CO}_{2}$ da margem de construção e margem de operação adotados foram, respectivamente, $0,1370 \mathrm{tCO}_{2} / \mathrm{MWh}$ e $0,5390 \mathrm{tCO} / \mathrm{MWh}$.

\subsection{Sistema de Geração Fotovoltaica}

Os sistemas de geração de energia fotovoltaica utilizados como estudo de caso foram elaborados por Valente (2019), apresentou a análise econômico-financeira da utilização de sistemas fotovoltaicos conectados à rede no estado do Pará. No estudo, Valente (2019) elaborou onze sistemas geração fotovoltaica conectado à rede, um para cada classe tarifária, a fim de observar qual classe tarifária apresenta menor custo com energia e estabeleceu um comparativo entre as diferentes classes tarifárias no estado do Pará. Os projetos foram considerados com vida útil de 25 anos.

Para a verificação de seu estudo, Valente (2019) implantou um sistema fotovoltaico conectado à rede em uma unidade comercial no município de Belém, Pará, conforme apresenta a Figura 4.

\footnotetext{
${ }^{3}$ Os fatores de emissão disponíveis no site do MCTIC são calculados utilizando ferramenta metodológica aprovada pelo Conselho Executivo do MDL. Disponível em: <https://www.mctic.gov.br/mctic/opencms/ciencia/SEPED/clima/textogeral/emissao_despacho.html> Acesso em: 20 out. 2019.
} 
Figura 4. Mapa de localização da edificação comercial em Belém, Pará

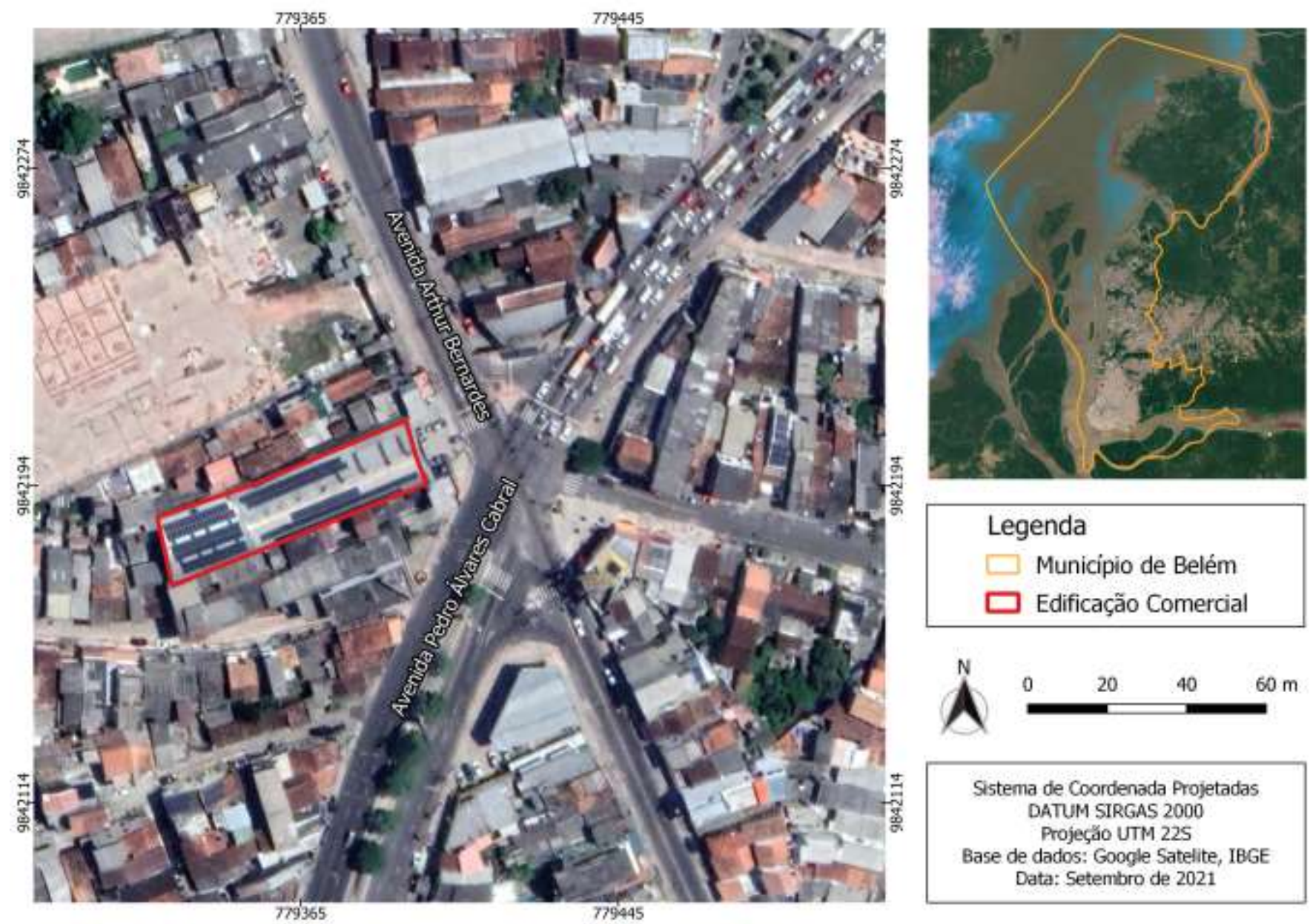

Fonte: Autores (2021).

No mapa de localização apresentado na Figura 4, nota-se os módulos fotovoltaicos na edificação comercial, sendo apresentado na Figura 5 a seguir, os módulos fotovoltaicos instalados na cobertura de telhas metálicas.

Figura 5. Módulos Fotovoltaicos instalados na edificação comercial em Belém, Pará.

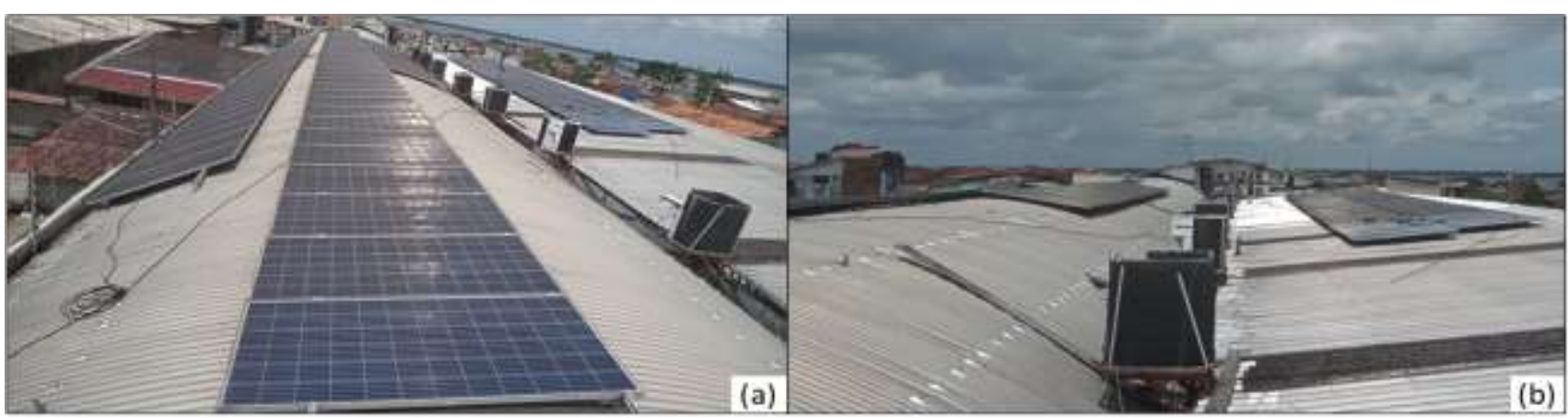

Fonte: Autores (2021).

Os indicadores econômicos observados no estudo de Valente (2019) foram Payback Simples, Payback Descontado, Valor Presente Líquido (VPL), Taxa Interna de Retorno (TIR) e Rentabilidade para as diferentes classes tarifárias. 
O Payback se refere ao tempo que o investimento inicial para implantação do projeto seja recuperado, ou seja, seu tempo de retorno. O Payback Simples é um método que não leva em consideração o valor do dinheiro no tempo, por outro lado, o Payback Descontado leva em consideração esse valor (Bischoff, 2013).

O Valor Presente Líquido (VPL) refere-se a soma do valor presente de todos os períodos que compõem o fluxo de caixa, nesse caso o período total foi de 25 anos, levando em consideração uma taxa de desconto definida no estudo. Se o VPL for positivo significa que o capital investido no projeto foi recuperado, caso aconteça o contrário e o VPL for negativo, significa que o projeto resultará em prejuízos (Bischoff, 2013).

A Taxa Interna de Retorno (TIR), também chamada de taxa de espera, é a taxa de juros projetada no fluxo de caixa do projeto do investimento analisado (Bischoff, 2013).

A Rentabilidade se trata da taxa de juros efetiva que será calculada com a conclusão do projeto, também representada pela taxa realizada (Bischoff, 2013).

\subsection{Elaboração de Cenários}

Considerando os dados obtidos na revisão de literatura em relação a Reduções Certificadas de Emissões (RCEs), serão considerados os cenários para recebimento dos créditos nos valores de: $10 \mathrm{US} \$ / \mathrm{tonCO}_{2}, 20 \mathrm{US} \$ / \mathrm{tonCO}_{2}$ e $30 \mathrm{US} \$ /$ tonCO $_{2}$, para as classes tarifárias apresentadas por Valente (2019), podendo caracterizar em relação aos valores, respectivamente, os cenários como: pessimista, neutro e otimista, tendo em vista que os valores pagos em RCEs não ultrapassam muito os 30 US\$/tonCO 2 , assim como foi considerado por Padilha (2009), apresentados na Tabela 1.

Tabela 1. Cenários de Referência.

\begin{tabular}{clcc}
\hline Cenário & \multicolumn{1}{c}{ Descrição } & Característica & Valor da RCEs (US\$/tonCO 2 ) \\
\hline 1 & com substituição para Geração Fotovoltaica & Pessimista & 10 \\
2 & com substituição para Geração Fotovoltaica & Neutro & 20 \\
3 & com substituição para Geração Fotovoltaica & Otimista & 30 \\
\hline
\end{tabular}

Fonte: Adaptado de "Determinação da potência mínima de termoelétricas para viabilização de projetos de mecanismos de desenvolvimento limpo no estado do Pará" de Padilha, 2009.

\subsection{Custos de um Projeto MDL}

Neste estudo considerou-se os investimentos referentes a implantação e a operação do projeto de acordo com as fases do ciclo do projeto MDL. Os investimentos serão calculados de acordo com a média dos custos apresentados por UNESA (2005) para projetos de MDL de pequena escala conforme apresentado na Tabela 2. 
Tabela 2. Estimativa dos custos por etapas do ciclo em projetos de pequena escala.

\begin{tabular}{|c|c|c|}
\hline Fase do Ciclo do Projeto de MDL & \multicolumn{2}{|c|}{ Faixa de Custos (US\$) } \\
\hline Desenvolvimento da Concepção do Projeto / Design & \multicolumn{2}{|c|}{$18.000-50.000$} \\
\hline Validação & \multicolumn{2}{|c|}{$10.000-30.000$} \\
\hline Negociação do Contrato & \multicolumn{2}{|c|}{$10.000-20.000$} \\
\hline \multirow{6}{*}{ Registro } & tCO2 anual & US\$ \\
\hline & $<=15.000$ & 5.000 \\
\hline & $>15.000 \mathrm{e}<=50.000$ & 10.000 \\
\hline & $>50.000 \mathrm{e}<=100.000$ & 15.000 \\
\hline & $>100.000 \mathrm{e}<=200.000$ & 20.000 \\
\hline & $>200.000$ & 30.000 \\
\hline \multicolumn{3}{|l|}{ Monitoramento } \\
\hline Verificação & \multirow{2}{*}{\multicolumn{2}{|c|}{$3.000-6.000 *$}} \\
\hline Certificação & & \\
\hline Expedição das Certificações - RCEs & \multicolumn{2}{|r|}{$\begin{array}{c}\text { Sobre o valor da RCE para gastos } \\
\text { administrativos }\end{array}$} \\
\hline Venda RCEs & \multicolumn{2}{|r|}{ Sobre o valor da RCEs } \\
\hline
\end{tabular}

Fonte: Adaptado de "Metodología para la implementación de los mecanismos flexibles de Kioto - Mecanismo de desarrollo limpio en Latinoamerica: guía latinoamericana del MDL: Programa Synergy" de Asociación Española de la Industria Eléctrica [UNESA] 2005.

*Custos anuais

\section{Resultados e Discussão}

Por meio da execução da metodologia de MDL AMS-I.D, foi possível quantificar as Reduções das Emissões de $\mathrm{CO}_{2}$, em $\mathrm{tCO}_{2} \mathrm{e} / \mathrm{ano}$, levando em consideração os dados apresentados no estudo elaborado por Valente (2019) e os valores obtidos no site do MCTIC.

No estudo de Valente (2019) foi utilizada a geração minoritária de 119,765 MWh/ano para cada uma das unidades consumidoras no ano inicial do projeto, sendo possível quantificar as reduções de emissões $\left(E R_{y}\right)$ em 52,52 tCO $2 / a n o$. Com esse valor referente a redução de emissões obtido com a geração do estudo de Valente (2019) foram calculadas as Reduções Certificadas de Emissões (RCEs) considerando os cenários e os valores em cada um deles, conforme apresentado anteriormente na Tabela 1, sendo possível obter os resultados dos cálculos das RCEs na Tabela 3.

Tabela 3. Quantificação das RCEs considerando as reduções de emissões no ano de implantação do projeto e os cenários analisados.

\begin{tabular}{ccc}
\hline Cenário & Característica & Valor da RCEs (US\$/tonCO 2$)$ \\
\hline 1 & Pessimista & 525,21 \\
3 & Neutro & $1.050,41$ \\
& Otimista & $1.575,62$ \\
\hline
\end{tabular}

Fonte: Autores, baseado em dados de "Determinação da potência mínima de termoelétricas para viabilização de projetos de mecanismos de desenvolvimento limpo no estado do Pará" de Padilha, 2009.

Com base na estimativa dos custos em cada etapa do ciclo do projeto em pequena escala apresentados por UNESA (2005) na Tabela 2, foi utilizada a média da faixa desses custos por fase do ciclo do projeto possibilitando estimar os investimentos para o projeto de MDL de pequena escala. Além disso, os valores de custo para a expedição e venda das RCEs foram calculados de acordo com os três cenários analisados, conforme apresentado na Tabela 4. 
Tabela 4. Custos considerado para o estudo conforme fase do projeto.

\begin{tabular}{ccc}
\hline Fase do Ciclo do Projeto de MDL & Custo considerado para o estudo (US\$) \\
\hline Desenvolvimento da Concepção do Projeto / Design & & $34.000,00$ \\
Validação & $20.000,00$ \\
Negociação do Contrato & $15.000,00$ \\
Registro & & $5.000,00$ \\
\hline Monitoramento & \\
Verificação & & $4.500,00^{*}$ \\
Certificação & \\
\hline \\
\hline \\
Expedição das Certificações - RCEs & Cenário 1 & $10,50^{*}$ \\
& Cenário 2 & $21,01^{*}$ \\
& Cenário 3 & $31,51^{*}$ \\
\hline & Cenário 1 & $47,27^{*}$ \\
& Cenário 2 & $94,54^{*}$ \\
\end{tabular}

Fonte: Autores, baseado em dados de "Metodología para la implementación de los mecanismos flexibles de Kioto - Mecanismo de desarrollo limpio en Latinoamerica: guía latinoamericana del MDL: Programa Synergy” de Asociación Española de la Industria Eléctrica [UNESA] 2005.

*Custos anuais

Os valores das RCEs e dos custos por fase do ciclo do projeto foram transformados para real (R $\$$ - moeda brasileira), considerando a cotação do dólar (US\$) de R $\$ 4,20^{4}$.

Considerou-se a influência dos custos de investimento da aplicação do projeto de MDL e as custos anuais do projeto durante toda vida útil do sistema de geração após o ano de implantação. Obteve-se, assim, os resultados que os cenários analisados com a aplicação do MDL apresentam em comparação com os dados de indicadores econômicos apresentados por Valente (2019) nas 11 unidades consumidoras de diferentes classes tarifárias.

Diante dos dados obtidos é possível analisar que o tempo de retorno, representado pelos indicadores Payback Simples e Payback Descontado, com a aplicação do projeto MDL nas unidades consumidoras de diferentes classes tarifárias não apresentaram alterações em nenhum dos cenários em comparação com o tempo de retorno apresentado por Valente (2019) que não possui a aplicação do MDL, conforme apresentado na Tabela 5. Foi possível observar que quanto menor a classe tarifária maior será o tempo de retorno do investimento inicial do projeto, o Payback simples da classe tarifária de menor valor, Residencial de Baixa Renda 30kWh, se dará em 6,34 anos e o mesmo indicador para a classe tarifária de maior valor, Tarifa Azul, se dará em 1,99 anos.

\footnotetext{
${ }^{4}$ Cotação do dólar comercial em 20/11/2019. Disponível em: https://economia.uol.com.br/cotacoes/cambio/dolar-comercial-estados-unidos/.
} 
Tabela 5. Indicadores econômicos Payback Simples e Payback Descontado para cada classe tarifária no estado do Pará sem e com aplicação do Projeto de MDL.

\begin{tabular}{|c|c|c|c|c|c|}
\hline \multirow{2}{*}{ Classe Tarifária } & \multirow{2}{*}{$\begin{array}{c}\text { Tarifa } \\
(\mathrm{R} \$ / \mathbf{k W h})\end{array}$} & \multicolumn{2}{|c|}{ Payback Simples (anos) } & \multicolumn{2}{|c|}{ Payback Descontado (anos) } \\
\hline & & Sem MDL & Com MDL* & Sem MDL & Com MDL* \\
\hline Residência Baixa Renda 30 kWh & 0,34 & 6,34 & 6,34 & 7,98 & 7,98 \\
\hline $\begin{array}{l}\text { Residência Baixa Renda } 31 \text { a } \\
\qquad 100 \mathrm{kWh}\end{array}$ & 0,59 & 4,08 & 4,08 & 4,78 & 4,78 \\
\hline Mercado Livre & 0,76 & 3,27 & 3,27 & 3,74 & 3,74 \\
\hline Rural & 0,77 & 3,20 & 3,20 & 3,66 & 3,66 \\
\hline $\begin{array}{l}\text { Residência Baixa Renda } 101 \mathrm{a} \\
\qquad 220 \mathrm{kWh}\end{array}$ & 0,88 & 2,86 & 2,86 & 3,23 & 3,23 \\
\hline $\begin{array}{l}\text { Residência Baixa Renda acima } \\
\qquad 220 \mathrm{kWh}\end{array}$ & 0,98 & 2,60 & 2,60 & 2,92 & 2,92 \\
\hline Residencial & 1,02 & 2,50 & 2,50 & 2,80 & 2,80 \\
\hline Comercial & 1,02 & 2,50 & 2,50 & 2,80 & 2,80 \\
\hline Industrial & 1,02 & 2,50 & 2,50 & 2,80 & 2,80 \\
\hline Tarifa Verde & 1,17 & 2,21 & 2,21 & 2,45 & 2,45 \\
\hline Tarifa Azul & 1,31 & 1,99 & 1,99 & 2,18 & 2,18 \\
\hline
\end{tabular}

* Os Cenários 1, 2 e 3 apresentaram os mesmos resultados.

Fonte: Autores, com uso de dados de "Análise de Indicadores Econômico Financeiro de Sistema Fotovoltaico Conectado à Rede Segundo a Tarifa de Energia" de Valente, (2019).

Os outros indicadores econômicos observados: VPL, TIR e Rentabilidade apresentaram alterações, em todas as unidades consumidoras de diferentes classes tarifárias, comparados aos valores dos mesmos indicadores apresentados no estudo de Valente (2019), conforme apresentado, respectivamente, nas Figuras 6, 7 e 8. As alterações apresentadas são de redução nos valores desses indicadores conforme os cenários analisados, os resultados obtidos no cenário pessimista foram os menores, apresentando um aumento gradativo conforme os próximos cenários, neutro e otimista.

Analisando da classe tarifária Residencial de Baixa Renda 30kWh que apresenta a menor tarifa, os resultados obtidos para o VPL sem e com a aplicação de MDL nos cenários 1, 2 e 3 foram, respectivamente, R\$ 864.288,16, R\$ 364.021,02, R\$ 386.126,32 e R\$ 408.228,57. Enquanto a classe tarifária que apresenta a maior tarifa, Tarifa Azul, apresenta os seguintes resultados para o VPL sem e com a aplicação de MDL nos cenários 1, 2 e 3, respectivamente, R\$ 4.551.213,65, R\$ 4.050.946,51, $\mathrm{R} \$ 4.073 .050,34$ e $\mathrm{R} \$ 4.095 .154,05$. Observou-se que quanto menor a classe tarifária mais significativa foi a redução dos indicadores econômicos, conforme a Figura 6. 
Figura 6. Gráfico do Valor Presente Líquido para diferentes classes tarifárias no estado do Pará sem e com aplicação de projeto de MDL.

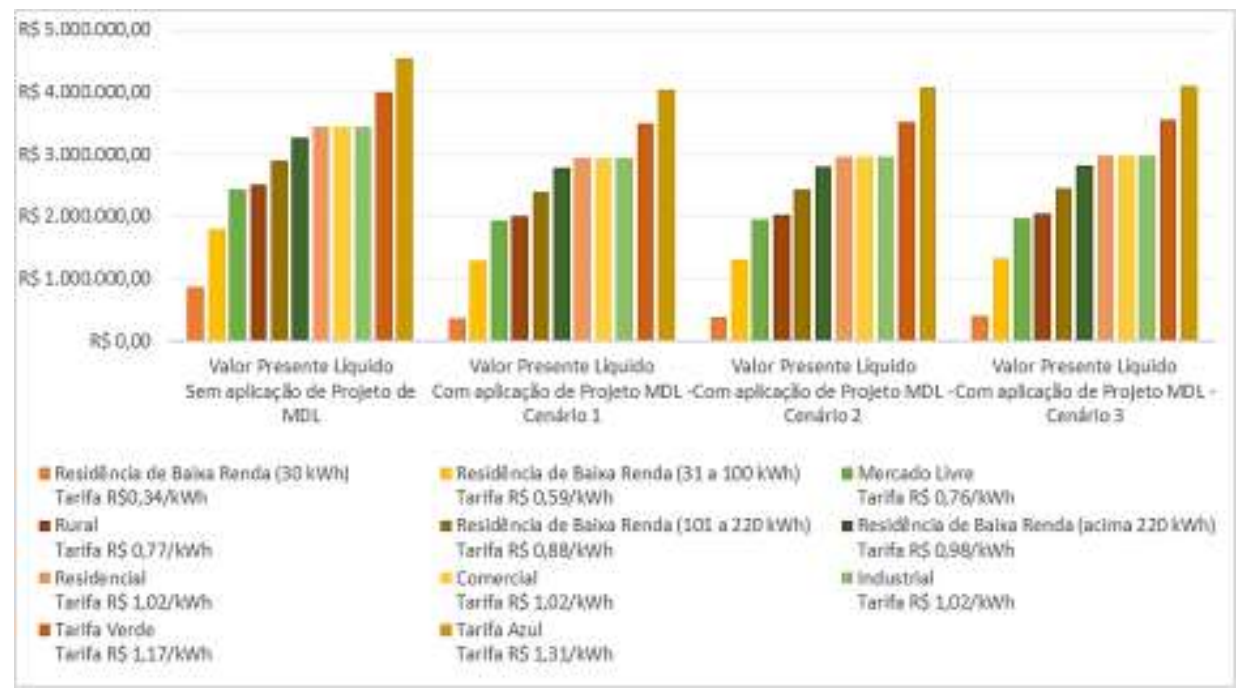

Fonte: Autores, com uso de dados de "Análise de Indicadores Econômico Financeiro de Sistema Fotovoltaico Conectado à Rede Segundo a Tarifa de Energia" de Valente, 2019.

O indicador econômico Taxa Interna de Retorno (TIR), conforme observado na Figura 7, não apresentou variação quando comparado os resultados entre os Cenários 1, 2 e 3 que possuem a aplicação do MDL, mas em relação aos resultados sem a aplicação do MDL, todas as classes tarifárias apresentam maiores resultados quando comparado aos cenários. A classe tarifária Residencial de Baixa Renda 30kWh, com a menor tarifa, apresenta a TIR sem e com a aplicação de MDL, respectivamente, $19 \%$ e 10\%. Enquanto a TIR da classe tarifária Tarifa Azul, a maior tarifa, sem e com a aplicação de MDL, respectivamente, 56,08\% e 35\%. Observando que a TIR apresenta maior variação para a classe tarifária de maior valor.

Figura 7. Gráfico da Taxa Interna de Retorno para diferentes classes tarifárias no estado do Pará sem e com aplicação de Projeto de MDL.

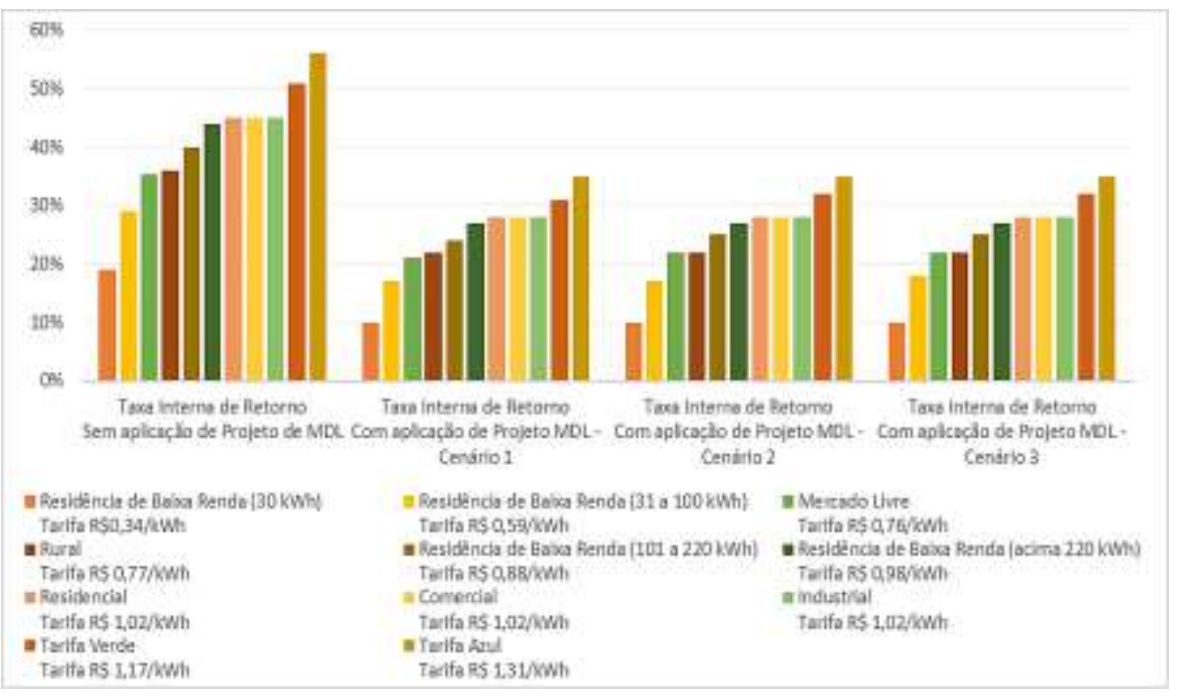

Fonte: Autores, com uso de dados de "Análise de Indicadores Econômico Financeiro de Sistema Fotovoltaico Conectado à Rede Segundo a Tarifa de Energia" de Valente, 2019. 
No caso da Rentabilidade, acontece o contrário, a Figura 8 demostra que a classe tarifária com menor valor de tarifa apresenta maior variação quando comparado com a classe tarifária de maior valor de tarifa com os resultados obtidos sem e com a aplicação do MDL de acordo os cenários 1, 2 e 3, A Residencial de Baixa Renda 30kWh tem Rentabilidade, respectivamente, $243 \%, 102 \%, 109 \%$ e $115 \%$. Enquanto a Tarifa Azul apresenta os resultados de Rentabilidade de $1.280 \%$, $1.140 \%, 1.146 \%$ e $1.152 \%$. Apesar dessas variações, os resultados de Rentabilidade em todos os cenários e classes tarifárias são elevados.

Figura 8. Gráfico da Rentabilidade para diferentes classes tarifárias no estado do Pará sem e com aplicação de Projeto de MDL.

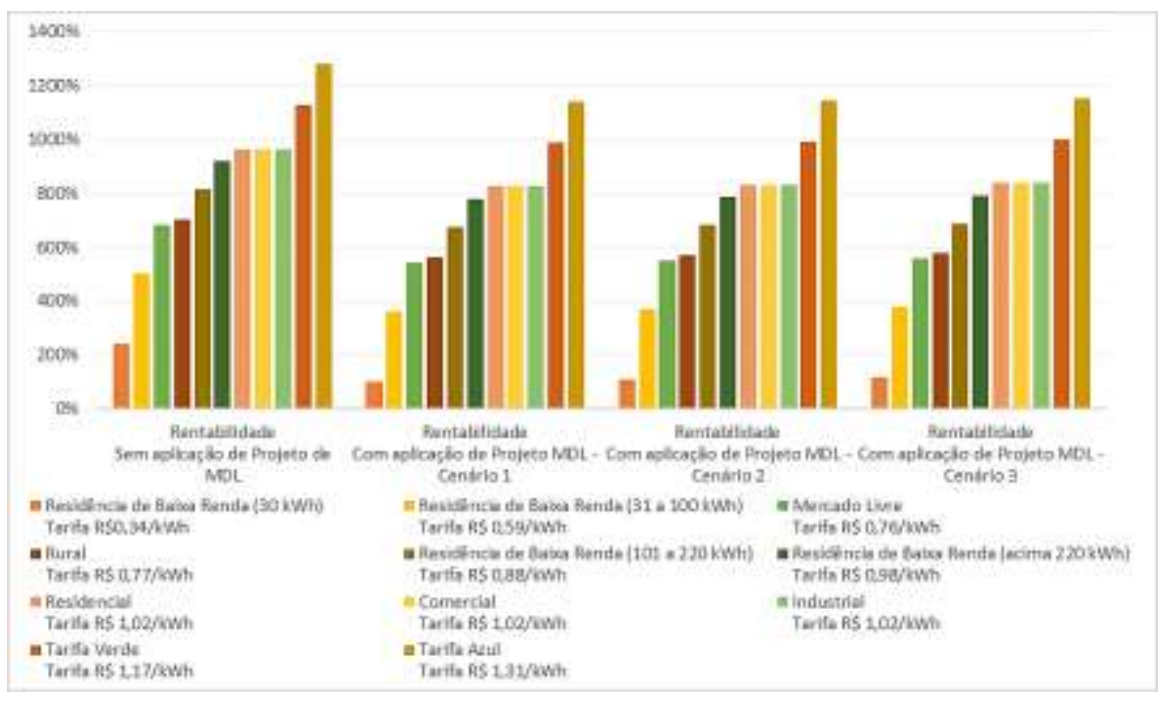

Fonte: Autores, com uso de dados de "Análise de Indicadores Econômico Financeiro de Sistema Fotovoltaico Conectado à Rede Segundo a Tarifa de Energia" de Valente, 2019.

Os valores numéricos obtidos para os indicadores VPL, TIR e Rentabilidade em cada um dos cenários analisados sem e com a aplicação do MDL nas 6 classes com menores valores das tarifários são apresentados na Tabela 6. 
Tabela 6. Valores dos indicadores econômicos obtidos para as seis menores classes tarifárias no estado do Pará sem e com aplicação de Projeto de MDL.

\begin{tabular}{|c|c|c|c|c|c|c|}
\hline & $\begin{array}{c}\text { R.B.R.*30 } \\
\text { kWh }\end{array}$ & $\begin{array}{c}\text { R.B.R.* } 31 \text { a } 100 \\
\text { kWh }\end{array}$ & $\begin{array}{l}\text { Mercado } \\
\text { Livre }\end{array}$ & Rural & $\begin{array}{c}\text { R.B.R.* } * 101 \text { a } 220 \\
\text { kWh }\end{array}$ & $\begin{array}{c}\text { R.B.R.* acima } 220 \\
\text { kWh }\end{array}$ \\
\hline Tarifa $(\mathbf{R} \$ / \mathbf{k W h})$ & 0,34 & 0,59 & 0,76 & 0,77 & 0,88 & 0,98 \\
\hline \multicolumn{7}{|c|}{ Sem aplicação de Projeto de MDL } \\
\hline VPL (R\$) & $864.288,16$ & $1.791 .950,19$ & $2.434 .843,14$ & $2.506 .590,18$ & $2.905 .178,60$ & $3.276 .254,73$ \\
\hline TIR & $19 \%$ & $29 \%$ & $35,38 \%$ & $36 \%$ & $40 \%$ & $44 \%$ \\
\hline Rentabilidade & $243 \%$ & $504 \%$ & $685 \%$ & $705 \%$ & $817 \%$ & $922 \%$ \\
\hline \multicolumn{7}{|c|}{ Com aplicação de Projeto MDL - Cenário 1} \\
\hline VPL (R\$) & $364.021,02$ & $1.291 .683,05$ & $1.934 .576,00$ & $2.006 .317,41$ & $2.404 .911,46$ & $2.775 .987,59$ \\
\hline TIR & $10 \%$ & $17 \%$ & $21 \%$ & $22 \%$ & $24 \%$ & $27 \%$ \\
\hline Rentabilidade & $102 \%$ & $363 \%$ & $544 \%$ & $564 \%$ & $677 \%$ & $781 \%$ \\
\hline \multicolumn{7}{|c|}{ Com aplicação de Projeto MDL - Cenário 2} \\
\hline VPL (R\$) & $386.126,32$ & $1.313 .786,88$ & $1.956 .679,83$ & $2.028 .429,46$ & $2.427 .015,29$ & $2.798 .091,42$ \\
\hline TIR & $10 \%$ & $17 \%$ & $22 \%$ & $22 \%$ & $25 \%$ & $27 \%$ \\
\hline Rentabilidade & $109 \%$ & $370 \%$ & $550 \%$ & $571 \%$ & $683 \%$ & $787 \%$ \\
\hline \multicolumn{7}{|c|}{ Com aplicação de Projeto MDL - Cenário 3} \\
\hline VPL (R\$) & $408.228,57$ & $1.335 .890,60$ & $1.978 .783,54$ & $2.050 .530,59$ & $2.449 .119,00$ & $2.820 .195,14$ \\
\hline TIR & $10 \%$ & $18 \%$ & $22 \%$ & $22 \%$ & $25 \%$ & $27 \%$ \\
\hline Rentabilidade & $115 \%$ & $376 \%$ & $557 \%$ & $577 \%$ & $689 \%$ & $793 \%$ \\
\hline
\end{tabular}

Fonte: Autores, com uso de dados de "Análise de Indicadores Econômico Financeiro de Sistema Fotovoltaico Conectado à Rede Segundo a Tarifa de Energia" de Valente, 2019.

*Residência de Baixa Renda

Os valores numéricos obtidos para os indicadores VPL, TIR e Rentabilidade em cada um dos cenários analisados sem e com a aplicação do MDL nas 5 classes com maiores valores tarifários são apresentados na Tabela 7.

Tabela 7. Valores dos indicadores econômicos obtidos para as cinco maiores classes tarifárias no estado do Pará sem e com aplicação de Projeto de MDL.

\begin{tabular}{|c|c|c|c|c|c|}
\hline & Residencial & Comercial & Industrial & Tarifa Verde & Tarifa Azul \\
\hline Tarifa $(\mathbf{R} \$ / \mathbf{k W h})$ & 1,02 & 1,02 & 1,02 & 1,17 & 1,31 \\
\hline \multicolumn{6}{|c|}{ Sem aplicação de Projeto de MDL } \\
\hline VPL (R\$) & $3.435 .384,41$ & $3.435 .384,41$ & $3.435 .384,41$ & 4.007.011,99 & $4.551 .213,65$ \\
\hline TIR & $45 \%$ & $45 \%$ & $45 \%$ & $50,79 \%$ & $56,08 \%$ \\
\hline Rentabilidade & $966 \%$ & $966 \%$ & $966 \%$ & $1127 \%$ & $1280 \%$ \\
\hline \multicolumn{6}{|c|}{ Com aplicação de Projeto MDL - Cenário 1} \\
\hline VPL (R\$) & $2.935 .117,27$ & $2.935 .117,27$ & $2.935 .117,27$ & $3.506 .744,85$ & $4.050 .946,51$ \\
\hline TIR & $28 \%$ & $28 \%$ & $28 \%$ & $31 \%$ & $35 \%$ \\
\hline Rentabilidade & $826 \%$ & $826 \%$ & $826 \%$ & $987 \%$ & $1140 \%$ \\
\hline \multicolumn{6}{|c|}{ Com aplicação de Projeto MDL - Cenário 2} \\
\hline VPL (R\$) & $2.957 .221,10$ & $2.957 .221,10$ & $2.957 .221,10$ & $3.528 .848,68$ & 4.073.050,34 \\
\hline TIR & $28 \%$ & $28 \%$ & $28 \%$ & $32 \%$ & $35 \%$ \\
\hline Rentabilidade & $832 \%$ & $832 \%$ & $832 \%$ & $993 \%$ & $1146 \%$ \\
\hline \multicolumn{6}{|c|}{ Com aplicação de Projeto MDL - Cenário 3} \\
\hline VPL (R\$) & $2.979 .324,81$ & $2.979 .324,81$ & $2.979 .324,81$ & $3.550 .952,39$ & $4.095 .154,05$ \\
\hline TIR & $28 \%$ & $28 \%$ & $28 \%$ & $32 \%$ & $35 \%$ \\
\hline Rentabilidade & $838 \%$ & $838 \%$ & $838 \%$ & $999 \%$ & $1152 \%$ \\
\hline
\end{tabular}

Fonte: Autores, com uso de dados de "Análise de Indicadores Econômico Financeiro de Sistema Fotovoltaico Conectado à Rede Segundo a Tarifa de Energia" de Valente, 2019.

Batista (2007) realizou um estudo de estimação do valor incremental do mercado de carbono nos projetos de fontes renováveis de geração de energia elétrica no Brasil, observou-se que os projetos de pequena escala muitas vezes não apresentam uma receita proveniente da comercialização de RCEs suficiente para remunerar os custos que envolvem as etapas do projeto, chamados no estudo de custos de transação. Isso pode ser devido aos projetos de pequena escala não possuir a capacidade de evitar grandes quantidades de emissões de GEEs os tornando menos atrativos economicamente. 
Apesar disso, a aplicação do projeto de MDL realizada nesse estudo apresentou viabilidade econômica ao sistema de geração fotovoltaica mesmo apresentando redução em alguns dos indicadores econômicos quando considerado o sistema sem a aplicação do projeto MDL. O VPL se manteve positivo caracterizando que as receitas ainda são maiores que as despesas e o projeto é viável, a TIR também se manteve dentro do considerável viável e a Rentabilidade ainda apresenta valores elevados. Além da viabilidade econômica, deve-se ser considerada a viabilidade ambiental que a adoção do projeto de MDL irá proporcionar.

Outro fator é a matriz energética do Brasil, composta em sua maioria por geração hídrica, uma fonte renovável de energia. Os dados de fator de emissão foram utilizados considerando essa fonte energética. Um projeto com fonte de energia não renovável, como exemplo a de combustíveis fosseis, irá obter maiores resultados em relação a emissões reduzidas, pois essa fonte possui maior geração de GEE.

No último relatório apresentado pela UNFCCC (MCTI, 2017) a respeito dos projetos de MDL no Brasil até janeiro de 2016, o total de projetos registrados classificados em pequena escala representavam 33\% dos projetos de MDL no país. Considerando a hipótese da utilização de 33\% de toda geração distribuída no Brasil de energia solar, com base em dados de 2018 apresentada nos Boletins de Monitoramento do Sistema Elétrico disponível no site do Ministério de Minas e Energia, para aplicação de projetos de MDL em pequena escala, seria possível quantificar as reduções de emissões $\left(E R_{y}\right)$ em $34.833,11$ $\mathrm{tCO}_{2} /$ ano com o potencial de comercialização de RCEs no Brasil apresentado na Tabela 8.

Tabela 8. Potencial de RCEs considerando a representação de projetos MDL de pequena escala no Brasil.

\begin{tabular}{|c|c|c|c|}
\hline Cenário & Característica & Valor da RCEs (US\$/tonCO 2 ) & Valor da RCEs (US\$/tonCO $\left.{ }_{2}\right)$ \\
\hline 1 & Pessimista & 10 & $348.331,07$ \\
\hline 2 & Neutro & 20 & $696.662,15$ \\
\hline 3 & Otimista & 30 & $1.044 .993,22$ \\
\hline
\end{tabular}

Fonte: Autores, baseado em dados de "Determinação da potência mínima de termoelétricas para viabilização de projetos de mecanismos de desenvolvimento limpo no estado do Pará" de Padilha, 2009.

Diante do apresentado na Tabela 8 é possível observar que a arrecadação de recursos financeiros a nível de país seria significativa e mais vantajosa em relação a aplicação de projetos em pequenas unidades consumidoras, como apresentado no estudo de Valente (2019), residencial, comercial e rural. Esse potencial seria ainda maior realizando uma aplicação mais abrangente em projetos de grande e pequena escala.

\section{Considerações Finais}

Este trabalho se propôs, como objetivo geral, estudar o uso de projetos de MDL em sistemas fotovoltaicos e a viabilidade da aplicação desses projetos. Para isso foi realizado o levantamento bibliográfico a respeito da metodologia e aplicação de projetos de MDL, sendo possível quantificar os investimentos necessários em cada fase do ciclo do projeto de MDL, calcular o retorno financeiro e analisar a diferença apresentada no retorno financeiro em cada unidade consumidora de classe tarifária diferente apresentado no sistema de geração fotovoltaica escolhido como base do estudo.

Com relação as dificuldades para o desenvolvimento do trabalho, o levantamento de dados a respeito da aplicação de projetos de MDL foi uma etapa difícil do estudo. Foi possível observar que ainda não existe muitos estudos voltados à aplicação de projetos de MDL no Brasil e os arquivos em relação as metodologias que podem ser utilizadas dependendo do tipo de projeto MDL disponíveis no site do MDL - UNFCCC estão disponíveis em inglês, o que demandou mais tempo na escolha da metodologia devido a realização da tradução desses materiais.

Tendo em vista os dados gerados nesse estudo, observou-se que a aplicação de projetos de MDL na geração de energia fotovoltaica conectada à rede apresenta viabilidade, porém os indicadores econômicos apresentam resultados inferiores 
se comparado aos projetos de geração fotovoltaica conectada à rede sem aplicação do MDL, o que diverge da hipótese levantada no início desse estudo.

Os resultados dos indicadores econômicos VPL, TIR e Rentabilidade tiveram redução mais significativa nos valores das unidades consumidoras com menores classes tarifárias. Os projetos se mantiveram viáveis, porém houve uma expressiva redução se comparado ao projeto sem a aplicação do MDL. Essa redução de valores dos indicadores econômicos foi amenizando à medida que a aumentou o valor da tarifa.

Pode-se considerar que esses resultados apresentariam uma viabilidade mais significativa em gerações superiores ao apresentado no estudo, considerando que quanto maior a geração de energia pela nova fonte utilizada no projeto MDL, maior será a quantidade de emissões reduzidas, possibilitando assim maior geração de créditos de carbono para comercialização em RCEs.

O ciclo de desenvolvimento do projeto de obtenção de certificação de MDL é um fator que dificulta a viabilidade deste tipo de projeto devido a sua complexidade, além do elevado investimento quantificado para cada fase do projeto. Outro fator a se considerar é a variação da cotação dos valores de comercialização das RCEs que pode favorecer a viabilização do projeto, como também pode ocasionar o efeito contrário e não favorecer a comercialização dos créditos.

Diante do exposto sobre o potencial de arrecadação da comercialização de créditos de carbono apresentados no Brasil, verifica-se que existe um potencial significativo de aquisição de recursos por meio de RCEs com a aplicação de projetos em pequena escala nos sistemas com geração solar de geração distribuída já instalados.

Em função de poucos estudos relacionados a aplicação de projetos de MDL, recomenda-se para trabalhos futuros a realização da aplicação de projetos de MDL em diferentes unidades consumidoras e em sistemas com diferentes gerações de energia para fazer o comparativo com baixa e alta geração. Por fim, sugere-se também a aplicação de projetos de MDL em sistemas de geração energética de fontes não renováveis, tendo em vista que esses apresentarão maiores resultados de crédito de carbono considerando que esses sistemas emitem mais GEE.

\section{Agradecimentos}

O presente trabalho foi realizado com apoio da Coordenação de Aperfeiçoamento de Pessoal de Nível Superior Brasil (CAPES) - Código de Financiamento 001. Agradece também ao PPDMU/UNAMA pelo apoio na presente pesquisa.

\section{Referências}

ABSOLAR - Associação Brasileira de Energia Solar Fotovoltaica. (2021). Energia solar atinge marca histórica e Brasil entra para grupo dos 15 países com maior geração. < https://www.absolar.org.br/noticia/energia-solar-atinge-marca-historica-e-brasil-entra-para-grupo-dos-15-paises-com-maior-geracao/>.

ANEEL - Agência Nacional de Energia Elétrica. (2012). Resolução Normativa No 482, de 17 de abril de 2012. Brasília: DOU de 19/4/2012.

ANEEL - Agência Nacional de Energia Elétrica. (2015). Resolução Normativa Nº 687, de 24 de novembro de 2015. Brasília: DOU de 02/12/2015.

Ayrão, V. (2018). Energia Solar Fotovoltaica no Brasil: Conceitos, Aplicações e Estudo de Caso. Rio de Janeiro: International Copper Association Brazil.

Batista, F. R. S. (2007). Estimação do Valor Incremental do Mercado de Carbono nos Projetos de Fontes Renováveis de Geração de Energia Elétrica no Brasil: Uma abordagem pela Teoria das Opções Reais. 2007. 199 p. Tese (Doutorado em Engenharia Industrial) - Pontifícia Universidade Católica do Rio de Janeiro, Rio de Janeiro.

Bischoff, L. (2013). Análise de Projetos de Investimentos: Teoria e Questões Comentadas. Ed. Ferreira.

Frondizi, I. M. R. L. (2009). O Mecanismo de Desenvolvimento Limpo: guia de orientação 2009. Rio de Janeiro: Imperial Novo Milênio: FIDES.

Lamberts, R., Ghisi, E., Pereira, C. D., \& Batista, J. O. (2010) Casa eficiente: consumo e geração de energia (Vol. 2). Florianópolis: UFSC, LabEEE.

Lopes, D. G. (2013). Análise de Sistemas Fotovoltaicos Conectados à Rede no Âmbito do Mecanismo de Desenvolvimento Limpo: Estudo de Caso dos Projetos da Chamada No13 da ANEEL. 2013. Tese (Doutorado em Planejamento de Sistemas Energéticos) - Universidade Estadual de Campinas, Campinas, SP. 
MCTI - Ministério da Ciência, Tecnologia e Inovações. (2017). Status dos Projetos do Mecanismo de Desenvolvimento Limpo (MDL) no Brasil: Última compilação do site da UNFCCC e da de <https://www.mctic.gov.br/mctic/opencms/ciencia/SEPED/clima/mecanismo_de_desenvolvimento_limpo/Mecanismo_de_Desenvolvimento_Limpo.html>.

Padilha, J. L. (2009). Determinação da potência mínima de termoelétricas para viabilização de projetos de mecanismos de desenvolvimento limpo no estado do Pará. 2009. Dissertação (Mestrado em Engenharia Mecânica) - Universidade Federal do Pará, Belém, PA.

Pereira, E. B., Martins, F. R., Abreu, S. L., \& Ruther, R. (2006). Atlas brasileiro de energia solar. São José dos Campos: INPE.

Pereira, E. B., Martins, F. R., Gonçalves, A. R., Costa, R. S., Lima, F. J. L., Ruther, R., Abreu, S. L., Tiepolo, G. M., Pereira, S. V., \& Souza, J. G. (2017). Atlas brasileiro de energia solar. São José dos Campos: INPE. <http://doi.org/10.34024/978851700089>.

Pinho, J. T., \& Galdino, M. A. (2014). Manual de engenharia para sistemas fotovoltaicos. Grupo de trabalho de energia solar - GTES. CEPEL - DTE CRESESB. Rio de Janeiro.

Ribeiro, M. S. (2005). O Tratamento contábil dos créditos de carbono. Tese (Livre Docência em Contabilidade Geral) - Faculdade de Economia, Administração e Contabilidade de Ribeirão Preto, Universidade de São Paulo, Ribeirão Preto. 10.11606/T.96.2006.tde-11082006-093115.

Ruther, R. (2004). Edifícios solares fotovoltaicos: o potencial da geração solar fotovoltaica integrada a edificações urbanas e interligada à rede elétrica pública no Brasil. Florianópolis: LABSOLAR.

UNESA - Asociación Española de la Industria Eléctrica. (2005). Metodología para la implementación de los mecanismos flexibles de Kioto - Mecanismo de desarrollo limpio en Latinoamerica: guía latinoamericana del MDL: Programa Synergy. [S. l.]: UNESA.

UNFCCC - United Nations Framework Convention on Climate Change. (1998). KYOTO PROTOCOL [...]. Kyoto, Japan.

UNFCCC - United Nations Framework Convention on Climate Change. (2014a). CLEAN DEVELOPMENT MECHANISM - Small-scale Methodology: AMSI.D - Grid connected renewable electricity generation. Version non $n^{\circ}$ 18, 2014 . <https://cdm.unfecc.int/methodologies/DB/W3TINZ7KKWCK7L8WTXFQQOFQQH4SBK>

UNFCCC - United Nations Framework Convention on Climate Change. (2014b). Methodological tool: Tool to calculate the emission factor for an electricity system. Version 07.0, nov. 2014. <https://cdm.unfccc.int/methodologies/DB/W3TINZ7KKWCK7L8WTXFQQOFQQH4SBK>.

UNFCCC - United Nations Framework Convention on Climate Change. (2016). CDM Methodology Booklet. (8a. ed.,) nov. 2016. ISBN 978-92-9219-165-8. <https://cdm.unfccc.int/methodologies/index.html>.

Valente, R. O. (2019). Análise de Indicadores Econômico Financeiro de Sistema Fotovoltaico Conectado à Rede Segundo a Tarifa de Energia. 2019.123 p. Dissertação (Mestrado em Desenvolvimento e Meio Ambiente Urbano) - Universidade da Amazônia, Belém.

Vieira, A. C. F., Barros, M. E. M. S., \& Toscano, R. A. U. (2019). (Des)comercialização das reduções certificadas de emissões dos projetos no Mecanismo de Desenvolvimento Limpo do Brasil. In A. C. Oliveira (Ed.), Ensaios nas ciências agrárias e ambientais 4 (pp. 35-48). Belo Horizonte, MG: Atena Editora. 10.22533/at.ed.4071916014.

Vinagre, M. V. A., Longo, F. M. V., Nascimento, A. C., Blasques, L. C. M., \& França, F. R. R. (2016). Energia Solar Fotovoltaica em Edifícios Históricos em Belém do Pará. Cadernos de Arquitetura e Urbanismo, 23(33), 59 - 75. 